\title{
Safety Perception of Users and Willingness to Pay for Safer Public Transport
}

\author{
Mahmut Esad Ergin ${ }^{1}$ \\ ${ }^{1}$ Istanbul Commerce University, Logistic Management Department, Istanbul, Turkey
}

\begin{abstract}
One of a city's most basic necessities is a safe public transit infrastructure. The expenses of traffic congestion can be reduced with an accessible and economical public transit system. The most effective strategy to manage present and future transportation demand is to increase the use of public transit and to move private car users to a pleasant, quick, punctual, and safe public transportation system. It is aimed with this study is that the user impression of public transportation was tried to be quantified in terms of property and life safety, and it was explored how much users would be willing to pay for a safer public transportation system by using binomial logit model approach. As a result of the study, in general, people believe that the system is insufficient in terms of safety. As the consumers' trip times' rise, the likelihood of switching to Future mode increases. In this scenario, it is reasonable to argue that lowering trip time will improve consumers' perceptions of the safety of public transportation. As the consumers' ages rise, so does their need for more pleasant and safe trips.
\end{abstract}

Keywords: Perception of users, willingness to pay analysis, binomial logit model, safety, travel behavior

\section{Introduction}

In order to establish a sustainable transportation system, it is necessary to eliminate transportation-traffic problems such as traffic congestion, geometric irregularities, waiting time in traffic, accessibility, mobility, and the damages caused by transportation to the environment. In order to reduce these problems, private vehicle users should be encouraged to use the public transportation system.

Sustainability of transportation is directly proportional to less traffic congestion and mobility in the city while using renewable resources and less damage to the environment. The only reason for traffic congestion is not the inadequacy of the offered supply, but the inability to accurately predict the future transportation demand and the poor management of the current and expected demand. One of the reasons for the increase in transportation demand is migration. In addition to the natural population growth rate, migration from rural to urban areas has been an important part of urbanization in the historical process and it still maintains its importance even though there is a decrease in the rate of migration in some countries. (Lall, v. d., 2006). However, migration is one of the most important problems, especially in Turkey, where the study was conducted. Due to the war in Syria, cities have experienced rapid growth under the influence of a rapid and large migration wave. However, migration is not a problem of the transportation system alone. Factors such as urban planning, land use change, and the behavior of users also affect the transportation system. Tseng and Rhor (2011) stated that migrants generally choose noncar-driving modes of travel including public transport and non-motorized modes such as cycling and waking. This means, the number of migrants increase, the demand for the public transport rises.

The best way to manage the current and future demand in the transportation system can be achieved by the efficient use of public transportation systems, and the shift of private vehicle users to a comfortable, fast, punctual and safe public transportation system. In order for private vehicle users to prefer the public transportation system, a quality public transportation system must be served. It is essential that quality public transport service has a good impact on users and increases their satisfaction. User satisfaction is obtained by various methods in the literature. One of them is the survey study as it is conducted in this study.

The quality of the public transport system is determined by criteria that can be easily measured such as capacity, travel time, travel cost, and some others that cannot be easily measured such as stress, safety, feeling fatigue, etc. Because there are more passengers in one car, public transportation provides a bigger danger of safety and security. The absence of appropriate and integrated measures increases the situation in developing countries (Joewono and Kubota, 2006).

Within the scope of this study, the user perception of the public transportation system was tried to be measured in terms of safety of property and life, and it was investigated how much the users could pay for a safer public transportation system. Thus, the priorities of the users will be determined and investment decisions can be made accordingly.

The structure of the paper is organized as follows. In the next section, previous studies are explained, and then brief information is given within the scope of the binomial logit model used in the study. Afterwards, the study area is described and data analysis and modeling are presented. In the fifth part, the results of the model estimated and predicted values are submitted and then in the last, discussion and conclusion part gives recommendation according to the predictions of the model.

\section{Previous Studies}

In a study conducted in Bilbao, Spain in 2010, a method is presented to describe and quantify the relationship between the scoring given to the system and the scoring given for certain service variables. Surveys were 
conducted to obtain users' perceptions and evaluations on service variables such as connections, accessibility, information, timing, employee courtesy, comfort, safety, and environmental impacts. As a result, an order of importance was made among the examined public transport service variables, and in all 3 modeling studies, line safety (in terms of journey time), bus stop adequacy, timing of the bus, its connection with other systems and frequency of voyages came first. It was emphasized that the improvements to be made should be made according to this order of importance (Del Castillo ve Benitez, 2012).

Rundmo et al. (2011) aimed to compare the relative importance of perceptions of transportation risks to nontransport risk perceptions, as well as to look into differences in worry, perceived control of transportation modes, trust in authorities' risk handling, safety motivation, and attitudes toward transportation safety. As a result of the study, when comparing respondents who frequently used private means of transportation to those who frequently used public modes, perceived control, knowledge about safety, and faith in authorities were shown to be considerably different.

In another study, Kawgan-Kagan and Daubitz (2017) it was aimed to determine the scope of perceptions about electric vehicles and to measure the relative effect of aspects that cause positive perceptions of electric vehicles. According to the results of the study, the perception of electric mobility varies among users.

Joewono and Kubota (2006) studied in order to learn more about how people involved in the operation of public transportation perceive safety and security issues. This view is utilized to establish an improvement agenda tailored to the needs of developing countries. They grouped the security issues into three groups: safety from crime, safety from accidents and perception of security. Result of the factor analysis of the surveys can be summarized as they developed an improvement agenda including management, technology and institutions.

Sukhov et al (2021) looked at the requirement and sufficiency of contentment with a range of service quality attributes for overall travel satisfaction, and we discovered that safety was the sole necessary criterion linked with high overall travel pleasure before the intervention. After the intervention, safety remained a required criterion, however it was combined with other requirements. Olsson et al (2020) aimed to look at how public transportation utilization, quality perceptions, and travel satisfaction differed over five generations and how they related to life satisfaction overall. Finally, they discovered that security/safety was an essential quality factor that can be linked to both travel and life satisfaction.

\section{Method}

A new investment choice can be made based on the outcomes of demand models. Models are a powerful tool for decision-makers. It serves as the foundation for decisions like which mode of transportation should be used at particular beginning and terminating places. Simultaneously, the model may be used to examine the impact of a modification in the transportation system on passenger behavior. In this context, mode choice models can address issues such as how users will react to a public transportation vehicle price increase, how users will behave if bus frequency is increased or decreased, and whether private vehicle owners' behavior will change as a result of improved public transportation. The probability of choosing a mode of transportation is estimated using the assumptions of random utility theory, which asserts that in the phase of split, each user makes rational decisions, has information about each mode of transportation, and understands which one would give the most benefit (Ergin and Tezcan, 2021).

The binomial logit model is a popular choice modeling strategy because it is simple to implement and comprehend. This theory posits that a person always chooses the option that maximizes his or her utility given a collection of options. The utility theory general rule was applied by Koppelman and Bhat (2006) as follows:

$\mathrm{U}\left(\mathrm{X}_{\mathrm{i}}, \mathrm{s}\right)>\mathrm{U}\left(\mathrm{X}_{\mathrm{j}}, \mathrm{s}\right)$

When the possibilities (alternative set comprises) are just $i$ and $j$, the individual will choose $i$ instead of $j$, according to Equation 1. The generalized form of the formula is given as Equation 2:

$\mathrm{P}_{\mathrm{r}}(1)=\frac{\mathrm{e}^{\mathrm{V}_{1}}}{\mathrm{e}^{\mathrm{V}_{1}}+\mathrm{e}^{\mathrm{V}_{2}}}$

$\mathrm{P}$ represents the probability of an alternative to be chosen and takes value between $0-1$. Logit model is convenient to apply for choice sets with two alternatives.

\section{Data and Modeling}

A survey study was conducted with a face-to-face interview method with a total of 175 people in the districts of Kadıköy, Beşiktaş, Şişli and Üsküdar, which are activity centers in Istanbul. The surveys were made after working hours. The questions asked in the survey study are divided into two parts: stated preferences (ST) and revealed preferences (RP) questions. In the survey study, along with socio-economic indicators, people were asked which transportation system they currently prefer, whether they are satisfied with the safety of the preferred transportation mode, and how much they can pay for a safer public transportation system. In the study, the satisfaction of the users was measured according to the 5point Likert scale.

The average age of the people surveyed is 29.7. As can be seen from the age groups chart, $64.6 \%$ of the people surveyed are between the ages of 20 and 34 . The youngest person participating in the survey is 15 years old, and the oldest is 68 years old. $67 \%$ of the people surveyed are male and $67 \%$ are single. In addition, the average household size was 3.09. It has been determined that $69 \%$ of the survey participants are working, 50\% are homeowners and

\section{Volume 11 Issue 1, January 2022}




\section{International Journal of Science and Research (IJSR) \\ ISSN: 2319-7064 \\ SJIF (2020): 7.803}

$45 \%$ have a private vehicle. According to the survey results, the monthly average household income is 5, 300 TL. According to the results of the survey, $41 \%$ of the trips made are home-work trips. The distribution of trips according to their purpose is given in Figure 1.

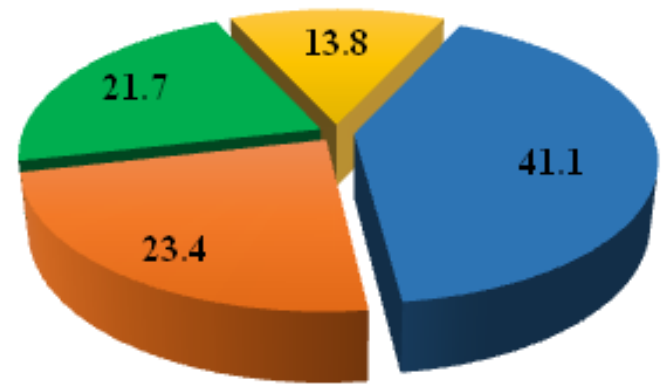

\section{- Home based work trips Home based school trips \\ - Home based other trips Non-home based trips}

Figure 1: Distribution of trips by purpose

In this study, the data obtained from the questionnaires were divided into groups. First of all, users were examined in two groups as public transport users and private vehicle users. Thus, the loyalty of the users of the public transport system and the probability of the users of private vehicles to shift to the public transport system were examined. In addition, the perception of the public transport system has been tried to be measured regardless of user discrimination. It has been analyzed how safe the public transportation system in terms of property and life safety in users' minds, and how much they can pay extra for it to be safer.

Socio-demographic data such as age, gender, marital status were entered into the model as variables. In addition, factors such as travel time and travel cost are also included in the model. In this study, the income of the users is not included alone, but a ration of travel cost over income. Thus, it is desired to examine how much more users are willing to pay for safer public transportation rather than their different needs. Likert scale questions asked to users were coded according to whether they were greater or less than the median value of 3 . The amount that users can pay extra for a safer public transport is usually around 1 Turkish Liras (TL), 2 TL and 5 TL. For this reason, these values were considered as critical points and accordingly, it was investigated whether each user would shift to a safer public transportation system in the new situation. The current mode is named Present, and the new mode, which will become more secure, is named Future.

\section{Results}

A single utility function is created in the model. This utility function belongs to the Future mode. According to the model, it was measured whether there was a shift from private car use to the Future mode and whether they remained in the Present mode. Accordingly, the coefficients of the variables in the model give the opportunity to compare the Future and Present modes. The modeling study was estimated 3 times as all users, public transport users and private vehicle users. Because a single model is created, the coefficients are alternative-specific, not generic.

Table 1: Binary Logit Model Results

\begin{tabular}{|c|c|c|c|c|c|c|}
\hline & \multicolumn{2}{|c|}{ Overall Sample } & \multicolumn{2}{|c|}{ Private Car Users } & \multicolumn{2}{|c|}{ Public Transport Users } \\
\hline Variables & Coefficient & t-stat. & Coefficient & t-stat. & Coefficient & t-stat. \\
\hline Travel time & $\mathbf{0 , 0 2 3}$ & 5,311 (a) & $\mathbf{0 , 0 1 9}$ & 2,142 (a) & $\mathbf{0 , 0 2 9}$ & 5,180 (a) \\
\hline Travel cost/Income & $-13,260$ & $-2,181$ (a) & $-11,039$ & $-1,049$ & $-16,205$ & $-2,090$ (a) \\
\hline Additional payment & $-0,504$ & $-7,264$ (a) & $-0,244$ & $-1,977$ (a) & $-0,651$ & $-7,101(a)$ \\
\hline Age & 0,068 & 4,460 (a) & 0,077 & 2,552 (a) & 0,070 & 3,404 (a) \\
\hline Gender & $-0,289$ & $-1,235$ & $-1,693$ & $-2,705$ (a) & $-0,489$ & $-0,178$ \\
\hline Marriage status & $-0,408$ & $-1,295$ & 0,093 & 0,148 & $-0,550$ & $-1,372$ \\
\hline Private car usage & 0,288 & 1,062 & - & - & - & - \\
\hline Home - Work trips & $-0,368$ & $-1,528$ & $-0,225$ & 0,444 & $-0,566$ & $-1,871(b)$ \\
\hline Average score & $-1,843$ & $-5,437$ (a) & $-3,523$ & $-4,210$ (a) & $-1,359$ & $-3,449$ (a) \\
\hline $\begin{array}{c}\text { Constant } \\
\end{array}$ & $-1,494$ & $-3,075$ (a) & $-1,148$ & $-0,927$ & $-1,551$ & $-2,666(a)$ \\
\hline No. of observations & \multicolumn{2}{|c|}{525} & \multicolumn{2}{|c|}{138} & \multicolumn{2}{|c|}{387} \\
\hline LL () & \multicolumn{2}{|c|}{271,950} & \multicolumn{2}{|c|}{68,757} & \multicolumn{2}{|c|}{191,186} \\
\hline LL (M) & \multicolumn{2}{|c|}{348,387} & \multicolumn{2}{|c|}{94,724} & \multicolumn{2}{|c|}{252,103} \\
\hline$-2 \mathrm{LL}$ & \multicolumn{2}{|c|}{152,875} & \multicolumn{2}{|c|}{51,935} & \multicolumn{2}{|c|}{121,834} \\
\hline$\rho^{2}$ & \multicolumn{2}{|c|}{0,219} & \multicolumn{2}{|c|}{0,274} & \multicolumn{2}{|c|}{0,242} \\
\hline
\end{tabular}

(a) significant at 95\% (1, 960), (b) significant at 90\% (1, 645), significant are written in bold.

According to the information given in Table 1, marital status and private car usage have no statistically significant effect on the safety perception of users of public transport.

Travel time: As the travel time increases, the probability of switching to a Future mode increases. For private vehicle users and public transport users, the journey time is statistically significant at the $95 \%$ confidence interval.
Travel cost/income: As the Travel Cost/Income increases, the probability of users staying with the Present mode increases across the sample. Travel cost has a negative impact on both the sample and public transport users. It is the variable with the highest weight in the model. Even if this variable is for the safety of property and life, it is the variable that has the greatest effect on the mode selection of users and it seems to have an effect

\section{Volume 11 Issue 1, January 2022}


independent of the state (quality, features) of the public transport system.

Additional payment: As the Additional Payment increases, the probability that all users, private vehicle users and public transport users in the sample are not tend to shift to the Future mode and remain in the Present mode.

Age: As age increases, the probability of users switching to the Future mode increases. This situation can be interpreted as an indication that as the age increases, people care more about the safety of their property and life.

Gender: Considering the effect of gender on the choice of species in terms of property and life safety, it is seen that there is no statistically significant difference in the $90 \%$ confidence interval for the overall sample and for public transport users.

Home-Work trips: Due to the negative sign of the HomeWork Travel variable coefficient, the probability of users staying in the Present mode increases as the purpose of the trip is work. Although this situation is closely related to the income level, it can be said that the public transportation users do not have any other alternative except for public transport.

Average score: The average score, its effect on mode selection is statistically significant across the all sample, within the $95 \%$ confidence interval for private vehicle users and public transport users. This shows that as the average score given by the user's increases, they will remain in the Present mode. This is an expected result because their current perception of the system is positive (relatively high), making them reluctant to switch to a Future mode.

\section{Discussion and Conclusion}

Users generally think that the system is not sufficient within the scope of Property and Life Safety. The probability of shifting to Future mode increases as the travel times of the users' increase. In this case, it can be concluded that reducing the travel time will have a positive effect on the perception of safety of the public transport of the users. The ratio of travel cost in income is seen as a more comparable variable. The ratio of travel cost over income is not statistically significant for private vehicle users, however, it is seen that for public transportation users, they tend to stay in the Present mode within the scope of safety as the ratio of travel cost in income increases. As the ages of the users increase, their desire to have a more comfortable and safe trips emerges. Female users want to get improved public transportation service more than male users as it expected as well.

A safe public transportation system is one of the most fundamental needs of a city. With an accessible, and affordable public transportation system, traffic congestion and the costs of traffic congestion can be avoided. In order to reduce the travel time, public transportation priority roads should be constructed, working hours should be arranged in order to manage the travel demand especially in the morning and evening peak hours, different working hours should be arranged on a sectoral basis, and a less crowded and thus safer public transportation system should serve. In addition, public transport system drivers should improve their driving behavior in a way that reduces the risk of traffic accidents. Finally, urban areas will be more livable areas as a result of a safer public transportation service and thus private vehicle drivers can shift to the public transport.

\section{References}

[1] Del Castillo, J. M. ve Benitez, F. G. (2012). "A methodology for modeling and identifying users satisfaction issues in public transport systems based on users surveys", Procedia-Social and Behavioral Sciences, 54, 1104-1114.

[2] Ergin, M. E., and Tezcan, H. O. (2021) Planned Special Event Travel Demand Model Development. International Journal of Engineering, Transactions B: Applications, 34 (2), 336-347. doi 10.5829/ije.2021.34.02b.05

[3] Friman, M. (2004). Implementing quality improvements in public transport, Journal of Public Transportation, Vol.7, Sayı: 4.

[4] Joewono, T. B., and Kubota, H. (2007). User satisfaction with paratransit in competition with motorization in Indonesia: anticipation of future implications, Transportation 34, 337-354 https://doi.org/10.1007/s11116-007-9119-7

[5] Kawgan-Kagan, I., and Daubitz, S. (2017). Individually constructed criteria for perception of urban transportation means - An approach based on Kelly's personal construct theory. Transportation Research Part F: Traffic Psychology and Behaviour, 44, 20-29. https://doi. org/10.1016/j. trf.2015.10.010

[6] Koppelman F. S., and Bhat, C. (2006) "A Self Instructing Course in Mode Choice Modelling: Multinomial and Nested Logit Models." U. S. Department of Transportation Federal Transit Administration,, p.18-19. https://www.ce.utexas.edu/prof/bhat/COURSES/LM_ Draft_060131Final-060630.pdf

[7] Lall, S. V., Selad, H. ve Shalizi, H. (2006). "Ruralurban migration in developing countries: A survey of theoretical predictions and empirical findings", World Bank Policy Research Working Paper, 3915.

[8] Olsson, L., Friman, M., Lättman, K., and Fujii, S. (2020) Travel and life satisfaction-From Gen $\mathrm{Z}$ to the silent generation, J. Transport Health, 18. https://doi.org/10.1016/j.jth.2020.100894

[9] Ortuzar, J. D. ve Willumsen, L. G. (2011). "Modelling transport: $4^{\text {th }}$ Edition", ISBN: 9781119993315. Birleşik Krallık. John Wiley \& Sons, Ltd.

[10] Rundmo, T., Nordfjærn, T., Iversen, H. H., Oltedal, S., and Jørgensenc, S. H. (2011) The role of risk perception and other risk-related judgements in transportation mode use. Safety Science, 49 (2), 226 235. https://doi.org/10.1016/j.ssci.2010.08.003

\section{Volume 11 Issue 1, January 2022


[11] Sukhov, A., Lattman, K., Olsson, L. E., Friman, M., and Fujii, S. (2021). Assessing travel satisfaction in public transport: A configurational approach, Transportation Research Part D, 93, 102732. https://doi.org/10.1016/j.trd.2021.102732

[12] Türkiye İstatistik Kurumu (TUIK). (2020). (05.11.2020, https://data.tuik.gov.tr/tr/main-categorysub-categories-sub-components $2 /$ )

[13] Tsang, Flavia and Charlene Rohr, (2011) The impact of migration on transport and congestion. Santa Monica, CA: RAND Corporation. https://www.rand.org/pubs/technical_reports/TR1187. html

[14] United Nations, (2018). World Organization Prospect. (05.11.2020,

https://population.un.org/wup/Publications/Files/WU P2018-Report.pdf)

Volume 11 Issue 1, January 2022

www.ijsr.net 